\title{
latrogenic intralenticular broken steroid implant: a case report
}

\author{
Jun Fai Yap', Yong Zheng Wai', Qi Xiong Ng${ }^{1}$ and Lik Thai Lim² ${ }^{2}$
}

\begin{abstract}
Background: This is a case report of an iatrogenic intralenticular broken steroid (Ozurdex ${ }^{\mathrm{TM}}$ ) implant in a patient with uveitis. There are only a few case reports on broken Ozurdex ${ }^{T M}$ implants in the vitreous cavity, with none of them involving the crystalline lens. A few authors have described the accidental injection of an Ozurdex ${ }^{\text {TM }}$ implant into the crystalline lens, but all of the implants remained in one piece in the lens and none of them were broken. We report an unusual case of an Ozurdex ${ }^{\mathrm{TM}}$ implant which was injected inadvertently into the crystalline lens, resulting in a broken Ozurdex ${ }^{\mathrm{TM}}$ implant with an entry and exit wound through the posterior capsule of the lens.

Case presentation: An ophthalmic trainee performed an Ozurdex ${ }^{\mathrm{TM}}$ intravitreal injection into a 48-year-old Asian man's right eye under aseptic conditions. This patient was then followed up for further management. On day 7 post-procedure, a slit lamp examination revealed that the Ozurdex ${ }^{\mathrm{TM}}$ implant was injected into the intralenticular structure of his right eye and had fractured into two pieces. The posterior capsule of the right lens was breached, with one half of the Ozurdex ${ }^{\mathrm{TM}}$ implant stuck at the entry and the other stuck at the exit wound of the posterior capsule. This patient underwent right eye cataract extraction and repositioning of the fractured implant; he made an uneventful recovery.

Conclusions: Ophthalmologists should be aware of the potential risk of injecting an Ozurdex ${ }^{\mathrm{TM}}$ implant into an anatomical structure other than the vitreous cavity. Adequate training and careful administration of the Ozurdex ${ }^{\mathrm{TM}}$ implant are necessary to avoid such a complication, which fortunately is rare.
\end{abstract}

Keywords: Ozurdex ${ }^{\mathrm{TM}}$ implant, Steroid implant, Intralenticular, Uveitis, Case report

\section{Background}

Ozurdex $^{\text {tw }}$ (Allergan Pharmaceuticals) is a sustained-release biodegradable steroid ocular implant containing $0.7 \mathrm{mg}$ dexamethasone. It is licensed in the UK and Malaysia for the treatment of macular edema secondary to retinal vein occlusion and non-infectious posterior segment uveitis [1]. The ZERO study [2] conducted in Germany was designed to evaluate the safety and reliability of intravitreal Ozurdex ${ }^{\text {tm }}$ injections. The result of the study revealed that there were no broken Ozurdex ${ }^{\mathrm{m}}$ implants and no intraoperative lens injuries were reported [2]. There are only a few case reports on broken Ozurdex ${ }^{\mathrm{Tm}}$ implants in the vitreous cavity, with none of them involving the crystalline lens [3-5]. A few authors have described the accidental injection of an Ozurdex implant into the crystalline lens, but all of the implants

\footnotetext{
* Correspondence: likthai@gmail.com

${ }^{2}$ Universiti Malaysia Sarawak (UNIMAS), Kota Samarahan, Sarawak, Malaysia Full list of author information is available at the end of the article
}

remained as one piece in the lens and none of them were broken [6-9].

We report an unusual case of an Ozurdex ${ }^{\text {tm }}$ implant which was injected unintentionally into the crystalline lens resulting in a broken Ozurdex ${ }^{\mathrm{Tm}}$ implant with an entry and exit wound through the posterior capsule of the lens.

\section{Case presentation}

A 48-year-old Asian man was treated with Ozurdex ${ }^{\text {Ta }}$ intravitreal injection for uveitis secondary to sarcoidosis in his right eye. The diagnosis of sarcoidosis was presumptively made as he had compatible clinical evidence of hypercalcemia with raised serum angiotensin-converting enzyme (ACE) and radiological manifestations, such as bilateral hilar adenopathy, on chest X-ray after excluding other diseases that may present similarly.

He initially complained of seeing floaters over his right eye. The visual acuity of his right eye was $6 / 24$ whereas his left eye was normally recorded as 6/6. The initial 
intraocular pressure (IOP) for both eyes were within the normal range ( $16 \mathrm{mmHg}$ bilaterally). A slit lamp examination revealed right eye perivascular sheathing and Standardization of Uveitis Nomenclature (SUN) grade 2 vitritis changes. Despite intensive topical steroid treatment for 6 months, the vitritis persisted with no significant IOP increment; hence, an Ozurdex ${ }^{\mathrm{T} T}$ intravitreal injection was planned.

An ophthalmic trainee performed the procedure under aseptic conditions using the standard technique under supervision. The trainee did not notice significant recoil force generated throughout the Ozurdex ${ }^{\mathrm{mi}}$ intravitreal injection.

On day 7 post-procedure, this patient had a routine follow-up visit at the medical retina clinic and the injected Ozurdex ${ }^{\mathrm{ma}}$ implant was found to be broken into two pieces and located intralenticularly with the entry site at the inferotemporal region, breaching the posterior capsule of the lens (Figs. 1 and 2). No damage to the surrounding eye structures or cataract formation was observed. A schematic diagram showing a sagittal view of the eyeball (Fig. 3) aids understanding of the entry and exit points of the broken implant into the lens. The visual acuity of our patient's affected eye at that clinic review was 6/9 on Snellen chart.

The proposed mechanism of this intralenticular Ozur$\operatorname{dex}^{\mathrm{Tn}}$ implant fracture with both entry and exit sites at different areas of the posterior capsule is the possible anterior rotation and recoil force generated as the Ozur$\mathrm{dex}^{\mathrm{ma}}$ implant was injected intravitreally with the direction of the injector pointed unintentionally toward the lens (instead of pointed toward the direction of the optic disc), thereby resulting in the above clinical findings. In order to reduce the recoil force, we suggest the

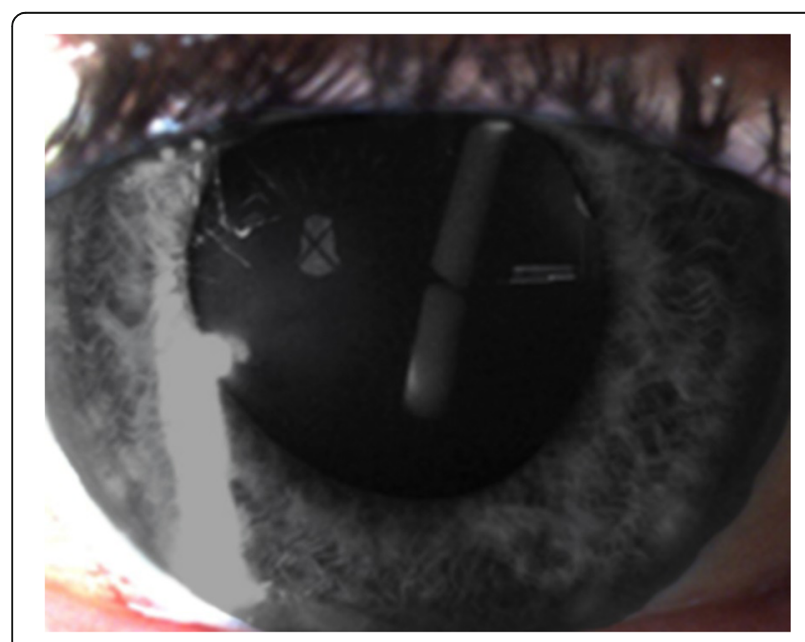

Fig. 1 The intravitreal injection was done inferotemporally; hence, the direction of the broken Ozurdex ${ }^{\mathrm{TM}}$ implant

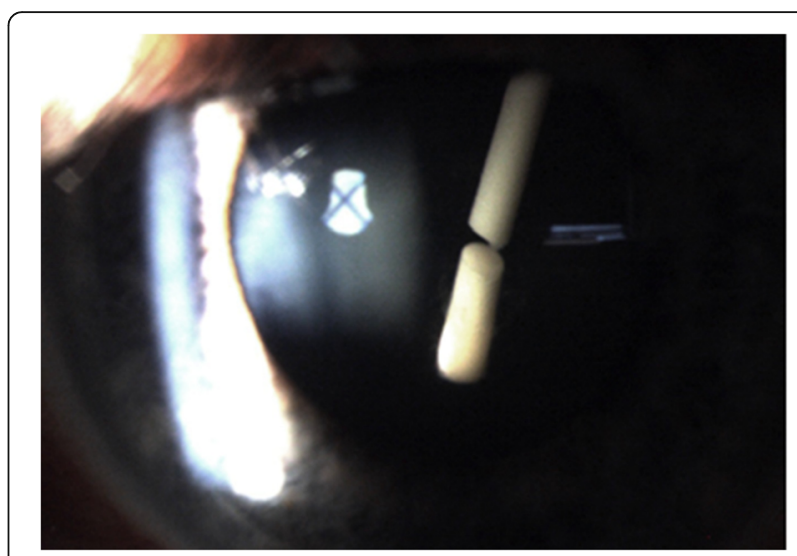

Fig. 2 Although this might not be apparent in the picture, a cursory examination revealed an entry site represented by the posterior capsular breach and an exit site posterior capsular breach of the shorter and longer broken implants, respectively

Ozurdex $^{\text {mit }}$ implant intravitreal injection be done toward the direction of the optic disc.

The posterior capsular breach occurred in two sites of the posterior capsule (as shown in Fig. 2), encroaching on the visual axis; a decision was made to proceed with the right eye cataract extraction and to reposition the fractured implant. A dispersive ophthalmic viscoelastic device (OVD) was used to help protect the corneal endothelium during phacoemulsification. The right eye natural lens was successfully removed as per usual phacoemulsification steps using divide and conquer technique. The broken Ozurdex $^{\text {Tx }}$ implant was repositioned through the alreadybreached posterior capsule into the vitreous cavity (which

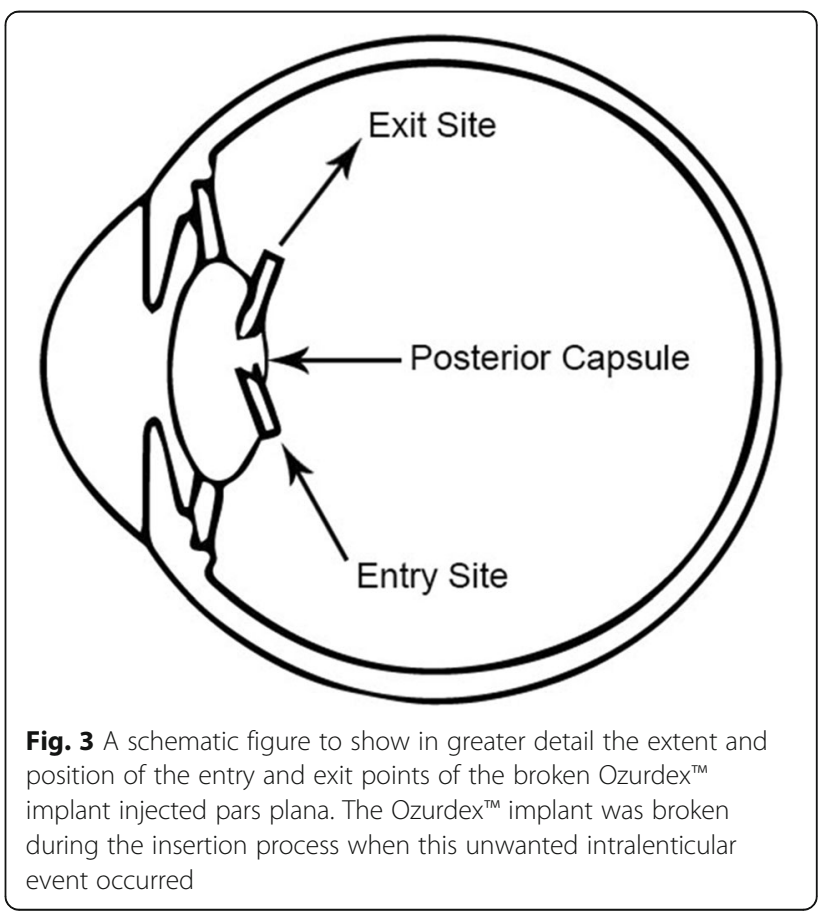


was the initial rightful anatomical position for the Ozur$\mathrm{dex}^{\mathrm{Tm}}$ implant) after the natural lens removal without vitreous loss. An intraocular lens was successfully placed in the capsular bag, after the broken Ozurdex ${ }^{\mathrm{Tm}}$ implant was repositioned into the vitreous cavity. Finally, a circular posterior capsule capsulorhexis was performed prior to closing up.

At 3-month follow-up, the lens remained in place and unaided visual acuity of our patient's right eye was 6/9 with no macular edema. No posterior capsular opacification occurred and the IOP of both eyes were not raised. No endophthalmitis or retinal detachment signs were noted. The uveitis resolved completely at 3-month follow-up with no vitritis changes on fundus examination, with right eye best corrected visual acuity of $6 / 6$ on Snellen chart.

\section{Discussion and conclusions}

To the best of our knowledge, this is the first case of iatrogenic intralenticular broken steroid $\left(\mathrm{Ozurdex}^{\mathrm{Tm}}\right)$ implant with an entry and exit site at different areas of the posterior capsule.

Despite a previous case report stating observation of a stable intralenticular broken Ozurdex ${ }^{\mathrm{Tm}}$ implant [6], a surgical approach was deemed appropriate due to the unusual nature of the intralenticular broken implant which was encroaching on the visual axis and the increased risk of cataract formation. With the emergence of microsurgical implant intravitreal injection procedures, clinicians should be aware of the potential risk of injecting the implant into an anatomical space other than the vitreous cavity. It is important to emphasize the fact that any intravitreal injection should be pointed toward the direction of the optic disc and not in the direction of the lens. In our case, the fracture of an Ozurdex ${ }^{\mathrm{Tm}}$ implant did not affect its efficacy as the vitritis had resolved completely after the phacoemulsification. Adequate training and careful administration of the Ozurdex ${ }^{\text {su }}$ implant are necessary to avoid such a rare complication.

\section{Acknowledgements}

The authors express their gratitude to UNIMAS for the research

administration and support.

\section{Funding}

Nil.

\section{Availability of data and materials}

The dataset supporting the conclusion of this article is included within the article.

\section{Authors' contributions}

LTL conceptualized the case report study. JFY, YZW, and QXN helped with the case write-up, literature search, manuscript preparation, and editing. LTL reviewed the final manuscript. All authors read and approved the final manuscript.
Ethics approval and consent to participate

Ethics approval and consent to participate was obtained, and the study was approved by the institutional ethics committee of Universiti Malaysia Sarawak (UNIMAS). UNIMAS/NC-21.02/03-02 Jld.3 (28).

\section{Consent for publication}

Written informed consent was obtained from the patient for publication of this case report and any accompanying images. A copy of the written consent is available for review by the Editor-in-Chief of this journal.

\section{Competing interests}

The authors declare that they have no competing interests.

\section{Publisher's Note}

Springer Nature remains neutral with regard to jurisdictional claims in published maps and institutional affiliations.

\section{Author details}

'Hospital Tuanku Ja'afar Seremban, Seremban, Negeri Sembilan, Malaysia.

${ }^{2}$ Universiti Malaysia Sarawak (UNIMAS), Kota Samarahan, Sarawak, Malaysia.

Received: 12 November 2018 Accepted: 1 April 2019

Published online: 06 May 2019

\section{References}

1. Haller JA, Bandello F, Belfort $R$, et al. Randomized, sham-controlled trial of dexamethasone intravitreal implant in patients with macular edema due to retinal vein occlusion. Ophthalmology. 2010;117(6):1134-46.

2. Schmitz K, Maier M, Clemens CR, et al. Reliability and safety of intravitreal Ozurdex injections. The ZERO study. Ophthalmologe. 2014;111(1):44-52.

3. Agrawal R, Fernandez-Sanz G, Bala S, et al. Desegmentation of Ozurdex implant in vitreous cavity: report of two cases. Br J Ophthalmol. 2014;98(7):961-3.

4. Roy R, Hegde S. Split Ozurdex implant: a caution. Can J Ophthalmol. 2013; 48(1):e15-6.

5. Donmez O, Parlak M, Yaman A, et al. Splitting of a dexamethasone implant (Ozurdex) following the injection. Case Rep Ophthalmol Med. 2013;2013: 247949. https://doi.org/10.1155/2013/247949.

6. Regan KA, Blake CR, Lukowski ZL, et al. Intralenticular Ozurdex $x^{\oplus}$ one year later. Case Rep Ophthalmol. 2017;8(3):590-4.

7. Valverde-Megías A, Hernández-Ruiz S, Cifuentes-Canorea P, et al. Intralenticular Ozurdex implant: what to do and how. J Fr Ophtalmol. 2018;41(4):e149-50.

8. Sekeroglu MA, Anayol MA, Koc F, et al. Intralenticular sustained-release dexamethasone implant: is it still effective on macular edema. Case Rep Ophthalmol. 2016:7(1):85-9.

9. Baskan B, Cicek A, Gulhan A, et al. Ozurdex completely located inside a crystallized lens - results of 14 months. Am J Ophthalmol Case Rep. 2016;4:38-40.
Ready to submit your research? Choose BMC and benefit from:
- fast, convenient online submission
- thorough peer review by experienced researchers in your field
- rapid publication on acceptance
- support for research data, including large and complex data types
- gold Open Access which fosters wider collaboration and increased citations
- maximum visibility for your research: over $100 \mathrm{M}$ website views per year
At BMC, research is always in progress.
Learn more biomedcentral.com/submissions 